\title{
Fuel Demand across UK Industrial Subsectors
}

\author{
Paolo Agnolucci ${ }^{a *}$ and Vincenzo De Lipsis ${ }^{a}$
}

\begin{abstract}
Heterogeneity is a theme acquiring more and more prominence in the energy economic literature from both a modelling and policy-making perspective. We show that useful empirical evidence on this subject can be obtained by applying a parsimonious multivariate cointegration analysis that makes use of the increasingly available time series data on energy demand. We find that there is substantial heterogeneity in the demand for fuels from UK firms belonging to different subsectors, with price and level of production having different degrees of importance in the fuel choice, and with evidence of both substitutability and complementarity between fuels. Moreover, we show that fuel demand for the industrial sector as a whole is considerably more elastic than most estimates presented in the literature, finding which has direct relevance for policies aimed at influencing industrial fuel consumption through fuel switching.
\end{abstract}

Keywords: Fuel demand, Energy demand, Elasticities, Industrial subsectors, Industrial sector, Cointegration, Heterogeneity

https://doi.org/10.5547/01956574.41.6.pagn

\section{INTRODUCTION}

A considerable amount of energy is used by the industrial sector across the world, yet econometric studies of industrial energy demand are surprisingly scarce, as argued in Bernstein and Madlener (2015). Following Pesaran et al. (1998), who advocated estimation of energy demand functions on a set of consumers that is as homogeneous as possible, the aim of this paper is to explore the possible advantages of adopting a cointegration estimation approach at a disaggregated level by making use of a standard dataset, collected by most national offices for statistics across the world (Eurostat, 2018).

We implement an approach introduced by Pesaran et al (1998) for a number of Asian countries using an annual dataset spanning 17 years, and, as far as we are aware, not implemented in the literature ever since, although a similar approach has been adopted in Møller (2017) discussed below. Our approach estimates fuel demand by taking advantage of the dynamic specifications typical of cointegration studies and the system-wide approaches, which are typical of studies based on the translog function. It implies modelling the demand for different fuels as shares in a cointegrating VAR system with as many cointegrating vectors as the number of fuels being modelled, each representing the long-run demand for a specific fuel. Our approach presents a number of important advantages and can be implemented by using standard software packages and readily available datasets. Firstly, a system approach enables us to model the simultaneous determination of demand for

a UCL Institute for Sustainable Resources, Central House, 14 Upper Woburn Place, London, WC1H 0NN.

* Corresponding author. Associate Professor. E-mail: p.agnolucci@ucl.ac.uk.

The Energy Journal, Vol. 41, No. 6. This is an open access article under the terms of the Creative Commons Attribution License (CC-BY), which permits use, distribution and reproduction in any medium, provided the original work is properly cited. All rights reserved. 
different fossil fuels within a consistent framework. Secondly, a VAR setting allows us to exploit the cross-equation restrictions implied by the VECM representation, which offer a useful means to reduce the number of parameters to estimate. Finally, additional gains in terms of degrees of freedom are ensured by the fact that we model shares rather than fuel intensities (like in Møller, 2017). This enables us to drop one demand equation from the system as fuel shares sum up to one.

We implement this methodological innovation for a number of UK industrial subsectors using data for the time period between 1990 and 2014. Fuel consumption in the industrial sector as a whole has received considerable attention in the literature, as testified in the reviews mentioned below, but estimation at the subsectorial level is surprisingly scarce. Bernstein and Madlener (2015) is the first study that makes use of subsectorial industrial data to estimate electricity demand elasticities in a cointegrating framework. This study progresses that line of enquiry by estimating demand for multiple fuels simultaneously, rather than for electricity on its own. By delivering this methodological innovation at a level of disaggregation largely unexplored in the literature, we are aiming to cast light on the existing lack of agreement on the magnitude of the elasticities associated with demand for energy fuels.

In addition, estimating the long-run equilibrium relationship between energy consumption and its main determinants enables us to investigate a number of key questions related to: 1) the dynamic impact of price changes and the presence of scale effects on the demand for energy fuels; and 2) the level of heterogeneity across industrial subsectors which are normally aggregated in typical empirical studies. ${ }^{1}$ Our main result, the emergence of substantial differences in the systematic behaviour of firms across subsectors, provides a note of caution to authors imposing homogeneity in the fuel demands across subsectors, those estimating fuel share elasticities for the industrial sector as a whole or focusing on energy consumption rather than fuel consumption. In addition, we find that price elasticities in the UK industrial sector are larger than many previous estimates in the literature, and we confirm that gas consumption is more sensitive to price variations than electricity consumption.

These conclusions are important not only from a modelling perspective, in a way which we would expect to be replicated for other countries, but also for policy-making purposes. As a matter of fact, the elasticities we present in this paper represent key information for policies that rely on price signals, e.g. the EU ETS and British policies such as the Climate Change Levy and the Carbon Reduction Commitment ${ }^{2}$, to achieve fuel substitution in a way which helps steering the economy towards decarbonisation. Such considerations arise as a direct consequence of our work with policy makers, given that the initial motivation for the analysis reported in this paper was the development of the new industrial energy demand model currently adopted by the UK government Department of Business, Energy and Industrial Strategy (BEIS), as part of their wider Energy Demand Model.

The structure of the paper is as follows. In Section 2 we discuss the existing literature and assess its main conclusions. After describing our methodological approach in Section 3, we discuss the data in Section 4, and in Section 5 we present our results in relation to unit root tests, cointegration analysis and estimation of fuel demand equations. Our findings are discussed in Section 6, while Section 7 offers concluding remarks.

1. Other approaches to produce estimates of long-run elasticities such as the Between Estimator recently advocated in Stern (2012) have the disadvantage of requiring panel datasets without being able to allow for coefficients to vary across units of analysis, in our case the industrial subsectors.

2. The aim of the CRC Scheme is to increase energy efficiency and cut emissions in large energy users in the UK's public and private sectors by mandating participants to purchase and surrender allowances for their emissions. This generates a direct incentive to substitute away from $\mathrm{CO}_{2}$-intensive fuels. In the case of the CCL, the substitution effects are less clear due to the fact that tax rate is not explicitly based on carbon content.

Open Access Article 


\section{LITERATURE REVIEW}

Demand for fossil fuels has been a topic of interest in energy economics for considerable time, with perhaps the policy motivations shifting from concerns about energy security and therefore substitution away from oil, to climate change and therefore substitution away from $\mathrm{CO}_{2}$ intensive fuels (Bardazzi et al. a 2016; Stern 2012; Åhman et al. 2016). Reflecting the policy relevance of this topic, the literature is large, with several published reviews which have surveyed the state of the work at different points in time - Bohi (1981), Bohi and Zimmerman (1984), Dahl (1993), Dahl (2011), Espey and Espey (2004), Stern (2012), Taylor (1975) and Taylor (1977). ${ }^{3}$ There is, however, little consensus about the exact magnitude of the elasticities for the demand of energy fuels (Bhattacharya, 1996). As an example, the interquartile range of long-run price elasticities for electricity in the studies surveyed by in Dahl (2011) covers values from -0.82 to -0.10 . Heterogeneity of consumers modelled in applied studies, consequent aggregation bias and adopted methodologies are all factors which are recognized to have an impact on estimated elasticities. These are discussed in turn in the remainder of this section.

The topic of heterogeneity has gained importance in energy economics, as testified by several contributions taking into account the impact of this factor, for example when modelling energy efficiency (Burnett and Madariaga, 2018), and the rebound effect (Frondel et al., 2012). As for estimation of energy demand, researchers have either adopted an econometric approach allowing for heterogeneity, e.g. through heterogeneous panel (Agnolucci, 2009) and shrinkage estimators (Andersen et al., 2011), or assumed a specific multilevel structure (Sharimakin et al., 2018). ${ }^{4}$ Using microdata is becoming a popular choice in the energy literature in order to account for heterogeneity, although the extent to which this is an effective strategy depends on the size of the sample in the survey. Traditional longitudinal data surveys might be helpful in dealing with heterogeneity, but only when a considerable number of annual observations are collected so that one is not confined to using traditional homogenous estimators. On the other hand, the growing availability of high-frequency datasets opens the possibility of adopting data-intensive approaches, such as machine-learning approaches (Barassi and Zhao, 2018), directly quantifying the heterogeneity across economic actors and econometric model structures.

Aggregation of parameters over micro units, which is related to heterogeneity within the sample is a widely explored topic in econometrics (Lee et al., 1990). ${ }^{5}$ The existence and the importance of the "aggregation bias", defined as the deviation of the macro parameters from the average of the corresponding micro parameters, depend on a number of factors such as the type of aggregation, the functional relationship, and the extent and type of heterogeneity (Blundell and Stoker, 2005). ${ }^{6}$ Whether or not aggregation bias is a problem is ultimately an empirical question, as the impact of aggregation can vary across parameters of a specific model. ${ }^{7}$ In the energy field, it is generally ac-

3. Considering the large number of studies and the fact that this branch of the literature has been reviewed extensively we do not review specific interfuel substitution studies in this section but we aim to place our study within the literature by discussing three topics which have been identified as having a great impact on the estimates found in the literature.

4. Application of either approach, however, is not free from its own complications. In the case of heterogeneous panels, for example, one requires time series for each cross-section to be of adequate length as otherwise estimates tend to be heavily influenced by outliers in the sample (Baltagi and Griffin, 1997).

5. It is important to stress that this aggregation issue is different from the one pointed out in Cleveland et al (2000) which refers to aggregation of fuel to compute energy demand.

6. Halvorsen and Larsen (2013) conclude that unless the assumptions behind perfect linear aggregation are fulfilled, aggregation bias is likely when inferring aggregate market demand in the presence of heterogeneous consumers.

7. As an example, aggregation bias was higher than $30 \%$ in the case of one parameter in the investment function estimated 
cepted that own price elasticities are smaller (in absolute value) and income elasticities larger when using aggregate data (Bohi, 1981 and Bohi and Zimmermann, 1984). Stern (2012) confirms that the magnitude of elasticities of substitution of energy as a production input tends to decrease with increasing levels of data aggregation.

The impact of adopted methodologies on estimated elasticities is also widely acknowledged in the literature. In the case of elasticities of substitution, estimates from cross-sectional regressions are generally largest, those from time-series smallest and those from fixed effects panel models lie somewhere in the middle (Stern, 2012). Studies adopting a single equation approach when modelling the demand for a specific fuel normally estimate cross-price elasticities by inserting the price of at least one alternative fuel in the equation. Some arbitrariness is intrinsically part of this approach, especially with regard to the choice of the additional fuel price. Comparison is complicated by the fact that different additional fuels are chosen in different studies for different countries. In Andersen et al. (2011), the prices of all other fuels are taken into account when modelling demand for gas in the industrial sector, while in several other instances no price of any other fuel is used. This assumes no substitution or complementarity across fuels, an assumption in evident contrast with the rationale of policies introduced to steer substitution across fuels. If not satisfied, this assumption is likely to cause a bias in the estimated coefficients bearing in mind the correlation between price of different fuels. As an example of this approach see Bernstein and Madlener (2015), Bjørner, Togeby and Jensen (2001) and Dilaver and Hunt (2011), when studying electricity consumption in Germany, Denmark, Korea and Turkey respectively.

System approaches have the advantage of incorporating all relevant fuels in the estimated model. Traditionally, they have been implemented through locally flexible functional forms, with the translog specification introduced by Christensen et al. (1971) being the workhorse in energy economics. Some recent applications include Bardazzi et al. (2016), Bjørner and Jensen (2002), Enevoldsen et al. (2007), Renou-Maissant (1999) and Serletis et al. (2010b). Other locally flexible functions used in the literature include the Normalised Quadratic cost function (Serletis et al., 2010a), the linear logit model introduced by Considine and Mount (1984) and applied in Steinbuks (2012) and Bjørner and Jensen (2002). Models based on global flexible functional forms, such as the Fourier and the Asymptotically Ideal Model (AIM) in Serletis and Shahmoradi (2008), have also been implemented. In several cases, for example Taheri and Stevenson (2002), industrial subsectors are used as units of a panel dataset, therefore imposing slope homogeneity across industrial subsectors, rather than exploring heterogeneity. Within a system approach, a few recent studies have employed cointegration analysis. Bernstein and Madlener (2015) estimated demand for electricity in 5 industrial subsectors in Germany by using a cointegrating VARs on the period 1970-2007. Agnolucci et al. (2017) modelled the total energy demand for the 8 UK industrial subsectors, demonstrating that theoretically plausible results can be obtained from a dataset starting in 1990. Møller (2017), which is probably the contribution closest to our research, estimated a set of cointegrating VARs to analyse the dynamics of two fuel intensities (that is electricity and all the other fuels divided by economic activity) in 8 industrial subsectors.

The lack of agreement on the size of estimated elasticities related to the industrial sector is also influenced by changing industrial structure. If substitution possibilities vary across firms, as it seems plausible, studies conducted at the aggregate industrial sector level will estimate, in absence of any aggregation bias, the average of firms' elasticities. Consequently, inter-country comparison

in Sasaki (1977), but higher than $100 \%$ in the case of another parameter. Similarly, Blundell et al. (1993) find significant aggregation bias in the case of income elasticities but no evidence for the price elasticities related to the demand for six food groups. 
at the industrial level becomes problematic, as it is influenced by the composition of the industrial sector. In addition, as the composition of the industrial sector in any given country changes across time, even elasticities for the industrial sector of a specific country are prone to show instability across time. These arguments show the importance of estimating demand elasticities at the most disaggregate level for which data are available. In our study, we do so for industrial subsectors in the UK, by adopting an innovative system methodology which consistently takes into account crossprice elasticities while estimating long-run equilibrium relationship.

\section{METHODOLOGICAL APPROACH}

Our study starts with the implementation of unit root testing based on ADF and the Zivot and Andrews (ZA) (1992) tests, with the latter allowing for one break in the deterministic components at an unknown point in time. We selected the number of lags in the testing equations based on the modified Akaike information criterion of $\mathrm{Ng}$ and Perron (2001), as it is robust to the presence of negative MA components in the error term, and chose the deterministic terms by assessing the Akaike and the Bayesian information criteria in models that include an intercept only or an intercept and a linear trend. Estimation of fuel demand is implemented through a Vector Autoregression (VAR) to model a system that describes the dynamics of fuel shares, prices and energy consumption. Indicating with $n$ the number of different fuels and with $d$ the fuel that is dropped from estimation and used as numeraire, our starting point is the long-term static relationship between fuel share and its determinants at time $t$

$$
w_{i t}=\varphi_{i}+\sum_{\substack{j=1 \\ j \neq d}}^{n} \beta_{i j} \ln \frac{P_{j t}}{P_{d t}}+\delta_{i} \ln e c_{t}+\gamma_{i} t+\varepsilon_{i t}
$$

where $w_{i t}$ indicates the logit transformation of the fuel $i$ share, that is $\mathrm{W}_{i t}=\log \left(\frac{s_{i t}}{1-s_{i t}}\right)$, the share being defined as $s_{i t}=\sum_{i} \frac{f c_{i t}}{e c_{t}}$, with $f c_{i t}$ being the consumption of fuel $i$ and $e c_{t}$ the level of energy consumption. The term $\varphi_{i}$ is an intercept, $P_{J t}$ the price of fuel $j$ and $P_{d t}$ the price of fuel $d$ used as numeraire, $t$ a deterministic time trend and $\varepsilon_{i t}$ is an error term representing deviations from the equilibrium. This specification is similar to the one derived from a translog cost function, with the difference that we focus on the fuel share rather than the cost share, and we introduce the level of energy consumption to capture the scale effect, as in Pesaran et al. (1998). We include a deterministic time trend as a proxy for changes in the preferences for a specific fuel, technological innovation, or any other factor influencing the fuel shares independently of relative prices and energy consumption. Choosing the logit transformation of fuel shares as dependent variable offers two advantages. First, under the assumption of an isoelastic functional form this transformation allows to estimate coefficients in each share equation that can be interpreted as elasticities of fuel consumption with respect to the independent variable. ${ }^{8}$ Second, the estimated system can readily be employed to generate forecasts, as done in BEIS (2017), since the resulting fuel shares are by construction bounded between zero and one.

Static formulations of fuel demands have several limitations as they ignore the dynamics of the adjustment process in inter-fuel substitution, which in particular is related to the costs of switching between fuels and the necessary modifications in the energy-consuming stock. We tackle this by

$$
\text { 8. Since } \frac{s_{i t}}{1-s_{i t}}=\frac{f c_{i t}}{\sum_{j \neq i} f c_{j t}} \text {, we have that } \frac{d\left(w_{i t}\right)}{d \log \left(f c_{i t}\right)}=1 \text {, so that, for instance, } \delta_{i}=\frac{d\left(w_{i t}\right)}{d \log \left(e c_{t}\right)}=\frac{d \log \left(f c_{i t}\right)}{d \log \left(e c_{t}\right)} \text {. }
$$


inserting the static model in a framework describing the dynamics towards the equilibrium, which is essentially the approach followed by Pesaran et al. (1998), who embed an interfuel substitution system similar to (1) in a cointegrating VAR. By doing so we can rigorously identify the long-run equilibrium demand for fuel via the Johansen procedure to estimate cointegrating vectors. While a time series approach has the clear advantage of offering a richer picture of the dynamics of firms' behaviour, allowing to distinguish short and long run responses to shocks, there is obviously a price to pay in terms of degrees of freedom, compared to a panel data model of the industrial sector, if elasticities are similar across subsectors.

Our fuel share demand model can be succinctly written in its VECM representation as

$$
\Delta \mathbf{x}_{t}=\Phi_{0}+\boldsymbol{\alpha} \boldsymbol{\beta}^{\prime} \mathbf{x}_{t-1}+\sum_{j=1}^{p-1} \Phi_{j} \Delta \mathbf{x}_{t-j}+\mathbf{u}_{t}
$$

where $\mathbf{x}_{t}$ is the vector of endogenous variables in the system, $\boldsymbol{\alpha}$ is the $m \times k$ matrix of adjustment coefficients, $\boldsymbol{\beta}$ is the $m \times k$ matrix of cointegrating vectors, both having as many rows as the number of endogenous variables in the system and as many columns as the number of cointegrating relationships, $\boldsymbol{\Phi}_{0}$ is a $m \times 1$ vector of deterministic terms, $p$ is the order of the corresponding VAR in levels, and $\mathbf{u}_{t}$ is a $m \times 1$ vector of zero mean error terms. We stress, in particular, that such VAR framework provides a useful means to save an appreciable amount of degrees of freedom, given that we can exploit the cross-equation restrictions implied by the VECM structure. As an example, in those cases where we have a system of 5 equations ( 2 fuel shares, 2 relative prices and energy consumption), with 2 cointegrating vectors, each containing 3 variables, we benefit from $6 \times 4=24$ overall cross-equation restrictions, that corresponds to almost 5 degrees of freedom saved for each equation.

Selection and estimation of the model specification are implemented in two steps. In the first step, we look for evidence of long-run relationships by testing for cointegration using the trace and the maximum eigenvalue tests of Johansen (1991). As to the deterministic terms in the cointegrating vector, we estimate both a model with an intercept only and one with a restricted trend, following Johansen (1992), as we have no strong reason to prefer one specification to the other. We select one lag only in our VECMs given the limited size of the available sample, but also because this choice turns out to be enough to remove any residual autocorrelation.

After establishing the evidence for two cointegrating relationships, in the second step we start by estimating models that are as general as possible, with two cointegrating vectors including fuel shares, relative fuel prices and energy consumption, and allowing for substitution to happen through cross-price elasticities and adjustment coefficients, i.e. a fuel share adjusting to the disequilibrium in the demand for the other fuel as well as to disequilibrium in its own demand. In determining the final specification, we impose only one assumption on the long-run relationship, that is a negative own-price elasticity in conformity with standard economic theory, but we leave cross-price elasticities unrestricted as different signs might reflect complementarities as well as substitutability between fuels. As a consequence, if own-price elasticity is positive we simplify the model by imposing a zero coefficient on the level of energy consumption within the cointegrating relationship and, in case the sign issue persists, also on the price of the fuel. After estimating by Maximum Likelihood the VECMs including the cointegrating vectors, we implement likelihood ratio tests to assess the statistical significance of the variables in the right-hand-side of the fuel share demand equation, their weak exogeneity, and the evidence for equality of cross-price elasticities in the two cointegrating vectors, a restriction that is incorporated in the final model if accepted. We augment the model with pulse dummies when substantial isolated outliers remain in the residuals, and study the residuals of 
the estimated VECMs to verify the absence of serial correlation, heteroscedasticity and deviations from the normality assumption.

\section{DATA}

Our dataset includes four sets of fuel prices and fuel consumptions, observed at an annual frequency between 1990 and 2014 for the eight industrial subsectors in the UK, which are listed in Table A1 of the Supplementary Information. It is worth clarifying that fuel consumption data include fuels purchased by the firms for their own consumption so that, as example, electricity auto-generated by the firms is not included as no electricity is purchased on the energy market. The level of energy consumption, which is computed as the sum of fuel consumption from data in BEIS (2016a), takes into account fuels used for the production of heat. Fuel prices were obtained by converting prices indices from BEIS (2016b), which incorporate all relevant taxes, into price levels by using information on the 2000 average fuel price. We then added the price of the EU ETS allowances based on the carbon intensity of oil, coal and natural gas, and the share of each sector covered by the EU ETS to compute a time series for each fuel price.

In all eight subsectors, there tends to be a fuel share that has been very small in size and rather constant across time, as shown in Figure A1 in the Supplemental Information ${ }^{9}$ We decide to exclude such fuel share from the model since its inclusion does not add information that is relevant to fuel substitution and may instead bias estimation. As a consequence, coal was dropped in the majority of the subsectors, namely CHE, ENV, FBT, PPP and TEX, while oil was dropped in MIN, NFM and OTH. A key to the acronyms of the industrial subsectors modelled in this study can be found in Table A1 of the Supplementary Information. Levels of consumption of the four fuels in the subsectors modelled in this study and the resulting total energy consumption can be seen in Figure A1 and Figure A2 in the Supplementary Information, respectively. Figure A3 displays the log of the relative fuel prices that are used in the modelling. In the figure, one can notice the difference between the time plots for the prices in NFM, MIN and OTH, which are built using coal as numeraire, and those for all the other subsectors, where oil is used as numeraire.

\section{ESTIMATION RESULTS}

\subsection{Results from Unit Root Tests}

Our unit root testing procedure points at the variables used in the modelling, i.e. fuel shares, relative fuel prices and energy consumption in UK industrial subsectors, being integrated of order 1 - I(1) — with some series characterized by structural breaks. More precisely, electricity shares appear to be I(1) in all but two subsectors-NFM and OTH—-see Table A2a in the Supplementary Information. One can however conclude that electricity shares in these two subsectors are I(1) after allowing for the presence of one break in trend through the application of a ZA test - see Table A2d. Evidence of integration of order 1 in the gas shares is more problematic - with this variable appearing to be I(2) in four subsectors - see Table A2b-but again one can conclude that the gas share in these four subsectors is I(1) based on results from a ZA test-see Table A2d. Also in the case of oil

9. Two exceptions to this empirical regularity can be found. In the case of OTH there is a considerable break in the share of oil as one can see in Figure A1 in the Supplemental Information and as a consequence this fuel rather than coal is dropped. In the case of PPP the size of coal and oil share are comparable, with coal being slightly larger. On the other hand, variation in the oil share is much larger than in the coal share therefore making coal a better candidate for being dropped in the analysis. 
and coal shares, the ZA tests suggests integration of order 1 in the two cases where the series appear to be I(2) based on ADF tests - see Table A2c and Table A2d. Similar results are obtained in the case of the other three variables, i.e. relative price of electricity and gas, and energy consumption, as one can see in Table A3 and Table A4 in the Supplemental Information. The outcome from the unit root tests implies that we can proceed to test for the existence of cointegration among the variables used in our study.

\subsection{Results from Cointegration Analysis}

Cointegration analysis points overall at the existence of two cointegrating vectors among our variables (see Table A5 in the Supplementary Information). ${ }^{10}$ In the case of NFM, both the trace and the maximum eigenvalue statistics suggest one cointegrating vector. Agnolucci et al. (2017) report that cointegration evidence in the NFM subsector differ from the results for the other subsectors, a finding they attributed to the fact that, there is complete overlap between the definition of this sector in the energy (DUKES) and in the ONS dataset from which economic data are extracted, contrary to all the other subsectors. Given the robust and consistent evidence we obtained from the other seven subsectors, we take the indication of one cointegrating vector in NFM as a spurious finding, and we estimate a VECM with two cointegrating vectors in all the eight industrial subsectors.

The results from applying the Johansen approach to the estimation of cointegrating relationships are displayed in Table 1. First of all, we stress how estimates for the NFM subsector are fairly similar to those for the other subsectors, with the exception of the coefficient on the gas price in the gas demand equation, therefore leading us to believe that it was reasonable to impose two cointegrating vectors in this subsector.Statistical significance of the long-run coefficients is assessed by running Likelihood Ratio tests (see Table 2). We observe that estimates for the own-price elasticities (for both electricity and gas) are highly significant in all but the TEX subsector. Price elasticity is always lower for electricity than for gas, with the exception of NFM and OTH. ${ }^{11}$ Cross-price elasticities are not statistically significant in two subsectors, ENV and OTH. Energy consumption and a linear deterministic trend are always statistically significant. When considered jointly, all variables in the two cointegrating vectors are always highly statistically significant, providing in this way a strong confirmation of the validity of our empirical model of the long-run fuel share demand. All the variables in the system appear endogenous based on weak exogeneity tests for prices and energy consumption implemented through Likelihood Ratio tests. We reject such hypothesis at 5\% significance level in all but the NFM subsector (Table 2).

Table 3 displays the outcome from implementing standard diagnostic tests on the VECMs used to produce the cointegrating vectors in Table 1 . Results confirm the overall validity of the selected models across subsectors. Residual autocorrelation, as measured by the LM test, is evident

10. More precisely, the maximum eigenvalue test suggests two cointegrating vectors in seven of the eight subsectors, while in four subsectors, namely CHE, ENV, FBT and PPP, this finding is also supported by the trace test. The trace test indicates one cointegrating vector in the MIN subsectors, and more than two cointegrating vectors in the OTH and TEX sector. The higher probability of size distortions of the trace test in finite samples is highlighted in Lütkepohl et al. (2001).

11. Peculiarities of fuel demands estimated for the NFM, OTH and TEX sectors might be due specific characteristics of the production process, therefore confirming the importance of a subsectorial analysis. On the other hand, data for OTH and NFM are of lower quality compared to the others. In the case of NFM, thias is related to a not perfect match between the definition of this sector in the energy dataset (DUKES) and that in the ONS dataset, as mentioned above. In the case of OTH, this is related to the apparent break in the oil consumption series, which suggests issues in the data collection process. The lack of statistical significance in the electricity price elasticity in the case of TEX might be related to the very small size of textile firms compared to the typical size of firms in other sectors.

Open Access Article 
only in the case of the TEX subsector, although only at the 5\% significance level. Heteroscedasticity is never detected by the White test, while deviation from normality emerges only in the MIN subsector, probably due to remaining outliers not explicitly taken into account by the included pulse dummies.

Table 1a: Long-run elasticities from the cointegrating vectors of the VECMs for electricity

\begin{tabular}{lcccccccc}
\hline & CHE & ENV & FBT & MIN & NFM & OTH & PPP & TEX \\
\hline Electricity Price & -0.22 & -0.74 & -0.49 & -0.44 & -1.39 & -1.90 & -0.61 & -0.22 \\
Gas Price & -0.47 & -0.08 & & -0.52 & 1.12 & -0.13 & 1.14 & -1.17 \\
Energy & -0.69 & 0.45 & & -0.84 & & -1.56 & -1.50 & -0.62 \\
Trend & & & & -0.01 & 0.04 & & & -0.03 \\
Constant & 4.40 & -2.95 & -0.55 & 5.94 & 1.94 & 15.75 & 11.29 & 2.63 \\
\hline
\end{tabular}

A key to the acronyms of the industrial subsectors can be seen in Table A1 in the Supplemental Information.

Table 1b: Long-run elasticities from the cointegrating vectors of the VECMs for gas

\begin{tabular}{lcccccccc}
\hline & CHE & ENV & FBT & MIN & NFM & OTH & PPP & TEX \\
\hline Electricity Price & -0.47 & -0.08 & & 0.48 & 1.12 & 0.14 & 0.32 & -1.17 \\
Gas Price & -1.37 & -0.71 & -0.67 & -1.68 & -0.62 & -1.31 & -1.61 & -2.40 \\
Energy & 2.12 & 1.16 & & 1.87 & & 0.38 & 1.82 & 1.52 \\
Trend & & & & 0.05 & 0.00 & & & -0.06 \\
Constant & -16.62 & -9.22 & -0.08 & -14.10 & -2.68 & -3.13 & -13.82 & -8.76 \\
\hline
\end{tabular}

A key to the acronyms of the industrial subsectors can be seen in Table A1 in the Supplemental Information.

Table 2: Likelihood Ratio tests for significance of the coefficients in the cointegrating vectors

\begin{tabular}{|c|c|c|c|c|}
\hline & CHE & ENV & FBT & MIN \\
\hline Own-price electricity & $4.80^{(*)}$ & $7.86^{(* *)}$ & $7.88^{(*)}$ & $8.41^{(* *)}$ \\
\hline Own-price gas & $32.32^{(* *)}$ & $12.25^{(* *)}$ & $5.58^{(*)}$ & $5.26^{(*)}$ \\
\hline Cross-price & $9.05^{(* *)}$ & 0.08 & & $13.30^{(* *)}$ \\
\hline Energy & $52.57^{(* *)}$ & $13.03^{(* *)}$ & & $16.60^{(* *)}$ \\
\hline Trend & & & & $9.80^{(* *)}$ \\
\hline All & $57.97^{(* *)}$ & $34.28^{(* *)}$ & $9.55^{(* *)}$ & $56.42^{(* *)}$ \\
\hline \multirow[t]{2}{*}{ Exogeneity } & $37.23^{(* *)}$ & $26.62^{(* *)}$ & $17.72^{(* *)}$ & $32.51^{(* *)}$ \\
\hline & NFM & ОТН & PPP & TEX \\
\hline Own-price electricity & $7.05(* *)$ & $21.85(* *)$ & $9.31(* *)$ & 0.52 \\
\hline Own-price gas & $22.69(* *)$ & $16.84(* *)$ & $13.37(* *)$ & $10.64(* *)$ \\
\hline Cross-price & $5.30(* *)$ & 1.63 & $16.65(* *)$ & $17.03(* *)$ \\
\hline Energy & & $44.76(* *)$ & $13.23(* *)$ & $9.00(* *)$ \\
\hline Trend & $22.39(* *)$ & & & $8.14(* *)$ \\
\hline All & $38.58(* *)$ & $82.00(* *)$ & $40.47(* *)$ & $50.91(* *)$ \\
\hline Exogeneity & 4.84 & $38.92(* *)$ & $21.53(* *)$ & $34.73(* *)$ \\
\hline
\end{tabular}

Significance level of $5 \%$ and $1 \%$ is indicated respectively by ${ }^{(*)}$ and ${ }^{(* *)}$. A key to the acronyms of the industrial subsectors can be seen in in Table A1 in the Supplemental Information.

Table 3: p-values of diagnostic tests for the VECMs used to estimate the cointegrating vectors

\begin{tabular}{lcccccccc}
\hline & CHE & ENV & FBT & MIN & NFM & OTH & PPP & TEX \\
\hline Serial Correlation & 0.14 & 0.94 & 0.24 & 0.29 & 0.79 & 0.72 & 0.13 & 0.05 \\
Heteroscedasticity & 0.49 & 0.55 & 0.69 & 0.36 & 0.86 & 0.56 & 0.47 & 0.63 \\
Normality & 0.96 & 0.84 & 0.68 & 0.00 & 0.96 & 0.87 & 0.89 & 0.79 \\
\hline
\end{tabular}

A key to the acronyms of the industrial subsectors can be seen in in Table A1 in the Supplemental Information. 


\section{DISCUSSION}

The estimated values of the cointegrating vectors and the related testing enable us to draw several insights into the features of the UK industrial fuel consumption. First of all, Likelihood Ratio tests in Table 2 indicate that the impact of fuel consumption determinants is consistently statistically significant across industrial subsectors. This result is a clear improvement on the statistical significance of energy demand models found in Agnolucci et al. (2017), Bernstein and Madlener (2015) and Møller (2017), all of which estimate cointegrating relationships at a similar level of disaggregation to the one in this paper. If we consider the work of Møller (2017), which is the study closest to ours in terms of methodology and focus of the enquiry, we notice that his estimates of own-price elasticity are non-statistically significant in 5 of 16 instances, whereas in our study this occurs only in one instance, electricity price in the TEX sector. Møller (2017) confirms that it is more challenging to deliver statistically significant cross-price than own-price elasticities, something we also observe in our study. Cross-price elasticities are not statistically significant in 8 out of the 16 cases estimated in Møller (2017). In our case, we are unable to deliver statistically significant coefficients in two subsectors, ENV and OTH.

As for the direction of the dynamic adjustment, we can exclude that prices and energy consumption are weakly exogenous in all the industrial subsectors, with the exception of NFM. This means that all variables contribute to the correction of past disequilibria in the two cointegrating relationships. This is at odds with results in Møller (2017), who found weak exogeneity of most of the variables in his model. Three reasons might explain the opposite conclusions. First of all, we adopt a different testing procedure: we assess the weak exogeneity of all variables but electricity and gas shares through a single test, whereas Møller (2017) tests the weak exogeneity of each variable separately, a strategy which may suffer from low power when the model contains many variables. ${ }^{12}$ Secondly, the Likelihood Ratio test may be influenced by our inclusion of total energy consumption in each subsector among the variables in the cointegrating VARs. Thirdly, it is also possible that our results are driven by the fact that the relative price of electricity and gas includes, from 2005 onwards, the EU ETS carbon price, which is likely to respond to disequilibria in the demand for electricity and gas in industrial subsectors, due to the limited coverage of the EU ETS. Regardless of the reasons causing our results, our findings justify the adoption of a system approach to cointegration, rather than implementing a single-equation ECM.

We observe that there are substantial differences across subsectors in the value of the longrun price elasticities. From a methodological point of view, our findings add to the existing evidence of the importance of heterogeneity in energy economics, as discussed in the literature review, and therefore against pooling across subsectors, or conducting modelling of the industrial sector as a whole. Our results confirm finding in the literature pointing at gas consumption typically being more price-elastic than electricity; see for example coefficients estimated by Bardazzi et al. (2016), Renou-Maissant (1999), Serletis et al. (2010a), Suh (2016) and Steinbuks (2012), displayed in Table $4 \mathrm{a}$ and Table $4 \mathrm{~b}$. From a modelling perspective, we observe that about half of electricity own-price elasticities falls in the fairly narrow range of $(-0.67,-0.74)$, with values estimated for CHE and TEX being considerably smaller $(-0.22)$ and the value in NFM and OTH considerably higher in absolute value, -1.39 and -1.9 , respectively. Also in the case of gas, half of the own-price elasticities falls

12. Møller (2017) implements 32 tests, i.e. 2 variables tested for each of the 2 cointegrating relationships in each of the 8 sectors. He finds statistical significance only in 3 of 32 coefficients estimates, so that his maintained assumption of weak exogeneity is largely accepted. Testing the weak exogeneity of individual variables is useful to distinguish the role of different variables in the equilibrium adjustment.

Open Access Article 
in a fairly narrow range, that is $(-1.68,-1.31)$. Elasticities in ENV, FBT and NFM are considerably smaller, ranging between -0.78 and -0.62 , while consumption in TEX is considerably more elastic, -2.40 . Leaving aside those cross-price elasticities that happen to be nonstatistically significant, namely in ENV and OTH, there is no clear prevalence between fuel complementarity and substitution across sectors, mirroring results obtained by Enevoldsen et al. (2007), Serletis et al. (2010b) and Pindyck (1979). This result point at the importance of subsectorial analysis, as the patterns of substitution and complementarity differ across subsectors.

Overall, our results indicate that electricity and gas consumption tends to be more price-elastic than established by previous studies focused on the UK. In the case of electricity, the average of our estimates weighted by the level of fuel consumption of each subsector is -0.82 , i.e. fairly similar to the value in Ros (2015) and Taheri Stevenson (2002) obtained by using panel data for the US industrial sector. Previous estimates for the UK are somehwat smaller, up to a maximum of -0.56 (Pyndick, 1999). Steinbuks (2012) estimates a price elasticity of -1.11 for electricity consumed in industrial heating processes, although electricity is rarely used for this purpose. Bernstein and Madlener (2015), who use a similar approach to our study, find that price elasticity in the German industrial subsectors falls between -0.52 and -0.30 when statistically different from zero. However, Burke and Abayasekara (2018) report a value of -1.34 for electricity price elasticity in the USA industrial sector, more than 50\% higher than our weighted average, by implementing an estimator focused on the long-run impact of the driving factors.

The weighted average of our gas price elasticities, i.e. -1.22 , is comparable to the value in Burke and Yang (2016) for the industrial sector in a panel of countries, the estimate in Hyland and Haller (2018) for Ireland, and falls in between the two estimates provided by Serletis and Shahmoradi (2008) for the US industrial sector. Steinbuks (2012) estimates an own-price elasticity of -0.94 for gas consumption used for heating processes in the UK, which represents the great majority of gas consumed in this sector (90\% of total gas consumption based on 2007 data presented in Steinbuks, 2012). Pyndick (1979) estimated a value of -1.44 . The fact that we tend to obtain a somewhat more elastic demand for both electricity and gas have two possible explanations. First, this can simply be the consequence of using data that have a higher level of disaggregation than many previous studies, as pointed out by Bohi (1981), Bohi and Zimmermann (1984) and Stern (2012). Second, contrary to much previous work, since we adopt an econometric approach that is explicitly designed to disentangle the long-run relationships between variables from the short-run dynamics, our estimates are very likely to capture more accurately the long-run effects of price changes, which are expected to be larger than in the short-run, due to substantial adjustment costs.

The occasional inclusion of a significant deterministic time trends in the cointegrating vectors accounts for factors that are not modelled explicitly, such as efficiency improvements, technological innovation for a specific fuel, or changes in the preferences for different fuels. As can be seen in Table 1, time trends are present only in three subsectors, i.e. MIN, NFM and TEX. The level of total energy consumption, on the other hand, is present in all subsectors but FBT and NFM. As one can appreciate from Figure A2 in the Supplementary Information, energy consumption has decreased throughout the period in all industrial subsectors, with the implications that a negative coefficient on energy consumption implies a historical increase, other things being equal, in the consumption of that specific fuel. As a matter of fact, this happens in all industrial subsectors except ENV in the case of electricity consumption, while gas consumption is positively related to energy consumption in all subsectors. It is also interesting to observe that in the subsectors where both energy consumption and linear trend are included in the final model, coefficients tend to have the same sign, therefore pointing at the influence of these two factors historically going in opposite directions. 
Table 4a: Estimates of gas own-price elasticities in the industrial sector found in the literature

\begin{tabular}{lcl}
\hline \multicolumn{1}{c}{ Source } & Estimate & \\
\hline Andersen et al. (2011) & $(-0.62,-0.31)$ & Long-run, UK, industrial sub-sectors \\
Bardazzi et al. (2016) & -0.82 & Italy \\
Burke and Yang (2016) & $(-1.09,-1.00)$ & International \\
Enevoldsen et al. (2007) & -0.11 & Nordic countries \\
Harvey and Marshall (1991) & -0.62 & UK \\
Huntington (2007) & $(-0.29,-0.15)$ & US \\
Hyland and Haller (2018) & -1.16 & Ireland \\
Pindyck (1979) & -1.44 & UK \\
Renou-Maissant (1999) & -0.65 & UK \\
Serletis et al. (2010) & -0.13 & UK \\
Serletis and Shahmoradi (2008) & $(-1.50,-1.01)$ & US \\
Steinbuks (2012) & $(-0.94,-0.28)$ & Long-run, UK, heating and all processes respectively \\
Suh (2016) & -0.20 & US \\
Taheri and Stevenson (2002) & -0.39 & US \\
Uri (1979) & -082 & UK \\
Uri (1982) & -0.91 & UK \\
Westoby (1984) & -1.06 & UK \\
Our weighted average & -1.22 & UK \\
\hline
\end{tabular}

Table 4b: Estimates of electricity own-price elasticities in the industrial sector found in the literature

\begin{tabular}{lcl}
\hline Source & Estimate & \\
\hline Bardazzi et al. (2016) & -0.46 & Notes \\
Bernstain and Madlener (2015) & $(-0.52,-0.30)$ & Long-run, industrial sub-sectors \\
Bjørner and Jensen (2002) & $(-0.13,-0.04)$ & Denmark \\
Bjørner et al. (2001) & -0.55 & Denmark \\
Burke and Abayasekara (2018) & -1.34 & Long-run, UK \\
Dilaver and Hunt (2011) & -0.16 & Turkey \\
Enevoldsen et al. (2007) & $(-0.28,-0.10)$ & Nordic countries \\
Harvey and Marshall (1991) & -0.06 & UK \\
Hyland and Haller (2018) & -0.31 & Ireland \\
Jamil and Ahmad (2011) & -1.22 & Long-run, Pakistan \\
Paul et al. (2009) & -0.40 & US \\
Pindyck (1979) & -0.56 & UK \\
Renou-Maissant (1999) & -0.31 & UK \\
Ros (2015) & $(-0.87,-0.52)$ & Long-run, US \\
Serletis et al. (2010) & -0.004 & UK \\
Steinbuks (2012) & $(-1.11,-0.23)$ & Long-run, UK, heating and all processes respectively \\
Suh (2016) & -0.11 & US \\
Taheri and Stevenson (2002) & -0.71 & US \\
Uri (1979) & -0.22 & US \\
Uri (1982) & -0.50 & UK \\
Westoby (1984) & -0.39 & UK \\
Our weighted average & -0.82 & UK \\
\hline & &
\end{tabular}

\section{CONCLUSIONS}

This paper offers some new insights on the long-standing topic of the industrial demand for energy fuels. The first novelty is methodological, as we illustrate the advantages of a cointegrating approach applied on a system of fuel shares, which has been previously applied only once but for the industrial sector as a whole rather than the industrial subsectors modelled in the study. By implementing the first cointegration analysis for a set of fuels shares estimated at a disaggregated industrial level, we showed that plausible and robust estimates of price elasticities can be obtained 
even from relatively short time series using a parsimonious but careful application of a system approach. Modelling a VECM for each of the eight industrial subsectors we obtained unequivocal evidence for the existence of two cointegrating relationships representing demand for electricity and gas. Compared to previous empirical contributions, our estimates present greater statistical significance, whether we consider the whole cointegrating vectors in general or the own-price elasticity in particular. As for the methodology we adopt, the validity and advantages of a system approach to estimation is confirmed by the steady rejection of the weak exogeneity hypothesis for energy prices and consumption across all subsectors.

Our results can be summarised as follows. Firstly, the magnitude of the weighted average of electricity and gas own-price elasticity for the industrial sector as a whole, -0.82 and -1.22 respectively, tends to be somewhat greater than the values previously estimated for the UK. This might be due to previous studies suffering from aggregation bias (as the consensus in the literature is that demand for fuels tend be less elastic when estimated at a more aggregate level), and to the fact that our estimation focuses on long-run fuel demand, which are expected to be more elastic as a result of substantial inter-fuel substitution costs in the short-term. Secondly, we obtained that price considerations are more important in gas than in electricity consumption, confirming previous understanding in the field. Thirdly, we found that demand for gas is positively related to total energy consumption while the opposite occurs for electricity demand, with this pattern being common to all subsectors, therefore showing the relevance of scale effects in the determination of fuel consumption. Fourthly, and presumably our most important finding, we uncovered substantial heterogeneity in the magnitude of own-price and cross-price elasticity of fuel demands across the eight industrial subsectors. Our results reveal unequivocal heterogeneity with respect to both the sign and the magnitude of price elasticities and scale effects. They provide a serious warning to those studies that aggregate data under the assumption of homogeneous coefficients across subsectors, like in panel data models. Moreover, in terms of the sign of cross-price elasticities, our work did not reveal any clear dominant evidence of substitutability over complementarity between fuels, in this confirming previous results in the literature. This last finding is likely the consequence of important differences in the ability of firms to respond to changes in prices, which is related to the specific characteristics of each subsector, and in particular to the different degree to which electricity and gas are used for different purposes. This type of evidence clearly suggests a careful assessment of the effectiveness of energy policies that aim at fostering fuel substitution but fail to account for the idiosyncratic features of each industrial subsector.

A number of extensions of our work naturally come to mind. First of all, we would expect our methodology to be employed across countries and industrial subsectors to start building a large body of evidence at subsectorial level that is useful for policy-making. This exercise would also be helpful to cast light on the value of some estimates, and on the extent to which they reflect country-specific peculiarities of the production process. Secondly, it would be interesting to investigate whether the long-run fuel demand functions have changed across time, through for instance the cointegrating approaches described in Bierens and Martins (2010) and Giratis et al. (2014) or by making use of the Kalman filtering (Agnolucci 2010). While the short horizon of our dataset discourages such analysis, longer time series available for other countries, e.g. Germany and Denmark, offer a potentially fruitful avenue for research. Thirdly, like studies implemented at a more aggregate level, our approach does not include any explicit technological characterization, although our subsectorial focus partially reduces such shortcoming. For this reason, it would be interesting to match our results with any bottom-up evidence on specific technological process, ideally taking into account the value of flexibility in consuming different fuels, or the value of technological irrevers- 
ibility normally explored in the real option value approach. Finally, another potentially interesting extension of this work would be to estimate elasticities across industrial sectors and countries, perhaps implementing the Between Estimator, as in Burke and Abayasekara (2018). This would imply having to impose homogeneity across members of the panel but would offer an alternative avenue to estimating long-run coefficients like those estimated in this study.

\section{ACKNOWLEDGMENTS}

The authors would like to thank Alessandro Arbib, Ruth Curran and Sarah Livermore for very engaging and constructive discussion throughout the research. Financial support from the UK Department of Business, Energy and Industrial Strategy (BEIS) is gratefully acknowledged. As the work discussed here was part of our contribution to the estimation of the industrial module of the BEIS Energy Demand Model, we are thankful to the Department for being selected for this task. Part of the time of Paolo Agnolucci and Vincenzo De Lipsis has been funded by the UK energy Research Centre (EP/L024756/1) and the Natural Environment Research Council (NE/M019799/1). We are indebted to the reviewers and the editor for advice and feedback during the reviewing process which considerably improved this article.

\section{REFERENCES}

Agnolucci, P. (2010). "Stochastic trends and technical change: The case of energy consumption in the British industrial and domestic sectors.” The Energy Journal 31:111-135. https://doi.org/10.5547/ISSN0195-6574-EJ-Vol31-No4-5.

Agnolucci, P. (2009). "The Energy Demand in the British and German Industrial Sectors: Heterogeneity and Common Factors.” Energy Economics 31:175-187. https://doi.org/10.1016/j.eneco.2008.08.005.

Agnolucci, P., V. De Lipsis, and T. Arvanitopoulos (2017). "Modelling UK sub-sector industrial energy demand." Energy Economics 67:366-374. https://doi.org/10.1016/j.eneco.2017.08.027.

Åhman, M., L.J. Nilsson, and B. Johansson (2016). "Global climate policy and deep decarbonization of energy-intensive industries.” Climate Policy 17:634-649. https://doi.org/10.1080/14693062.2016.1167009.

Andersen, T.B., O.B. Nilsen, and R. Tveteras (2011). "How is demand for natural gas determined across European industrial sectors?” Energy Policy 39:5499-5508. https://doi.org/10.1016/j.enpol.2011.05.012.

Baltagi, B.H. and J.M. Griffin (1997). "Pooled estimators vs. their heterogeneous counter- parts in the context of dynamic demand for gasoline" Journal of Econometrics 77:303-327. https://doi.org/10.1016/S0304-4076(96)01802-7.

Barassi, M. and Y. Zhao (2018). "Combination Forecasting of Energy Demand in the UK." The Energy Journal 39(SI1): 209-38. https://doi.org/10.5547/01956574.39.SI1.mbar.

Bardazzi, R., F. Oropallo, and M.G. Pazienza (2015). "Do manufacturing firms react to energy prices? Evidence from Italy." Energy Economics 49:168-81. https://doi.org/10.1016/j.eneco.2015.01.014.

BEIS (2017). Updated Energy and Emissions Projections 2016, London: Department for Business, Energy and Industrial Strategy.

BEIS (2016a). Digest of UK Energy Statistics (DUKES), London: Department for Business, Energy and Industrial Strategy.

BEIS (2016b). Quarterly Energy Prices, London: Department for Business, Energy and Industrial Strategy, Table 3.3.2 and 3.1.1.

Berndt, E.R. and D.O. Wood (1975). "Technology, prices and the derived demand for energy" Review of Economics and Statistics, 57:259-68. https://doi.org/10.2307/1923910.

Bernstein, R. and R. Madlener, (2015). "Short- and Long-Run Electricity Demand Elasticities at the Subsectoral Level: A Cointegration Analysis for German Manufacturing Industries”. Energy Economics 48:178-187. https://doi.org/10.1016/j. eneco.2014.12.019.

Bhattacharya, S.C. (1996). “Applied general equilibrium models for energy studies” Energy Economics 18:145-164. https:// doi.org/10.1016/0140-9883(96)00013-8.

Bierens H.J. and L.F. Martins (2010). "Time-Varying Cointegration” Econometric Theory, 26:1453-1490. https://doi. org/10.1017/S0266466609990648. 
Bjørner, T.B., and H.H. Jensen (2002). "Interfuel substitution within industrial companies: An analysis based on panel data at company level” The Energy Journal 23:27-50. https://doi.org/10.5547/ISSN0195-6574-EJ-Vol23-No2-1.

Bjørner T.B., M. Togeby, and H.H. Jensen (2001). "Industrial companies' demand for electricity: evidence from a micropanel.” Energy Economics 23:595-617. https://doi.org/10.1016/S0140-9883(00)00084-0.

Blundell, R., P. Pashardes, and G. Weber (1993). "What do we learn about consumer demand patterns from micro data?" American Economic Review 83: 570-97.

Blundell, R. and T.M. Stoker (2005). Heterogeneity and aggregation Journal of Economic Literature 43:347-391. https://doi. org/10.1257/0022051054661486.

Bohi, D.R. (1981). Analyzing Demand Behavior: A Study of Energy Elasticities. Baltimore, MD: Johns Hopkins Press.

Bohi, D.R. and M. Zimmerman (1984). “An Update on Econometric Studies of Energy Demand.” Annual Review of Energy 9:105-154. https://doi.org/10.1146/annurev.eg.09.110184.000541.

Burke, P.J. and A. Abayasekara (2018). "The price elasticity of electricity demand in the United States: A three-dimensional analysis.” The Energy Journal 39:123-145. https://doi.org/10.5547/01956574.39.2.pbur.

Burke, P.J. and H. Yang (2016). "The price and income elasticities of natural gas demand: International evidence." Energy Economics 59:466-474. https://doi.org/10.1016/j.eneco.2016.08.025.

Burnett, J.W. and J. Madariaga (2018). “A Top-Down Economic Efficiency Analysis of US Household Energy Consumption” The Energy Journal 39:1-30. https://doi.org/10.5547/01956574.39.4.jbur.

Christensen, L.R., D.W. Jorgenson, and L.J. Lau (1971). "Transcendental logarithmic production frontiers." The Review of Economics and Statistics 55:28-45. https://doi.org/10.2307/1927992.

Cleveland, C.J., R.K. Kaufmann, and D.I. Stern (2000). "Aggregation and the role of energy in the economy" Ecological Economics 32:301-317. https://doi.org/10.1016/S0921-8009(99)00113-5.

Considine, T.J. and T.D. Mount (1984). "The Use of Linear Logit Models for Dynamic Input Demand Systems.” The Review of Economics and Statistics, 66:434-443. https://doi.org/10.2307/1924999.

Dahl, C. (2011). A Global Survey of Electricity Demand Elasticities. 34th IAEE International Conference: Institutions, Efficiency and Evolving Energy Technologies. Stockholm.

Dahl, C. (1993). A Survey of Energy Demand Elasticities in Support of the Development of the NEMS. Washington D.C.: US Department of Energy.

Dilaver Z. and L. Hunt (2011). "Industrial Electricity Demand for Turkey: A Structural Time Series Analysis.” Energy Economics 33:426-436. https://doi.org/10.1016/j.eneco.2010.10.001.

Enevoldsen, M.K., A.V. Ryelund, and M.S. Andersen (2007). "Decoupling of industrial energy consumption and $\mathrm{CO}_{2}$ emissions in energy intensive industries in Scandinavia." Energy Economics 29:665-692. https://doi.org/10.1016/j. eneco.2007.01.016.

Espey, J. and M. Espey (2004). "Turning on the Lights: A Meta-Analysis of Residential Electricity Demand Elasticities." Journal of Agricultural and Applied Economics 36:65-81. https://doi.org/10.1017/S1074070800021866.

Eurostat (2018). Simplified energy balances—annual data [nrg_100a], Brussels: Eurostat.

Frondel M., N. Ritter, and C. Vance (2012). "Heterogeneity in the rebound effect: Further evidence for Germany." Energy Economics, 34:461-467. https://doi.org/10.1016/j.eneco.2011.10.016.

Giraitis, L., G. Kapetanios, and T. Yate (2014). "Inference on stochastic time-varying coefficient models." Journal of Econometrics 179:46-65. https://doi.org/10.1016/j.jeconom.2013.10.009.

Halvorsen, B. and B. M. Larsen (2013). "How serious is the aggregation problem? An empirical illustration." Applied Economics 45:3786-3794. https://doi.org/10.1080/00036846.2012.732690.

Harvey, A.C. and P. Marshall (1991). "Inter-fuel substitution, technical change and the demand for energy in the UK economy.” Applied Economics 23:1077-1086. https://doi.org/10.1080/00036849100000011.

Huntington, H.G. (2007). "Industrial natural gas consumption in the United States: an empirical model for evaluating future trends.” Energy Economics 29:743-759. https://doi.org/10.1016/j.eneco.2006.12.005.

Hyland M. and S. Haller (2018). "Firm-Level Estimates of Fuel Substitution: An Application to Carbon Pricing." The Energy Journal 39:71-97. https://doi.org/10.5547/01956574.39.6.mhyl.

Johansen, S. (1991). "Estimation and Hypothesis Testing of Cointegration Vectors in Gaussian Vector Autoregressive Models." Econometrica 59: 1551-1580. https://doi.org/10.2307/2938278.

Johansen, S. (1992). "Determination of Cointegration Rank in the Presence of a Linear Trend", Oxford Bulletin of Economics and Statistics 54: 383-397. https://doi.org/10.1111/j.1468-0084.1992.tb00008.x.

Lee, K.C., M.H. Pesaran, and R.G. Pierse (1990). “Testing for Aggregation Bias in Linear Models.” Economic Journal 100:137-50. https://doi.org/10.2307/2234191.

Møller, N.F. (2017). "Energy demand, substitution and environmental taxation: an econometric analysis of eight subsectors of the Danish economy." Energy Economics 61:97-10. https://doi.org/10.1016/j.eneco.2016.10.004. 
Paul A., E. Myers, and K. Palmer (2009). A Partial Adjustment Model of U.S. Electricity Demand by Region, Season, and Sector, RFF DP 08-50, Washington, DC: Resources for the Future. https://doi.org/10.2139/ssrn.1372228.

Pesaran, H., R. Smith, and T. Akiyama, (1998). Energy demand in Asian developing economies. Oxford: Oxford University Press.

Pindyck, R.S. (1979). "Interfuel Substitution and the Industrial Demand for Energy: An International Comparison." The Review of Economics and Statistics, 61:169-179. https://doi.org/10.2307/1924584.

Renou-Maissant, P. (1999). "Interfuel competition in the industrial sector of seven OECD countries." Energy Policy 27:99110. https://doi.org/10.1016/S0301-4215(99)00006-3.

Ros, A. (2015). An Econometric Assessment of Electricity Demand in the United States Using Panel Data and the Impact of Retail Competition on Prices, NERA: New York.

Sasaki, K. (1977). “An Empirical Analysis of Linear Aggregation Problems.” Journal of Econometrics 7:313-331. https:// doi.org/10.1016/0304-4076(78)90057-X.

Serletis, A., G.R. Timilsina, and O. Vasetsky (2010a). "International evidence on sectoral interfuel substitution." The Energy Journal 1-29. https://doi.org/10.5547/ISSN0195-6574-EJ-Vol31-No4-1.

Serletis, A., G.R. Timilsina, and O. Vasetsky (2010b). "Interfuel substitution in the United States." Energy Economics 32:737-745. https://doi.org/10.1016/j.eneco.2010.01.013.

Serletis, A. and A. Shahmoradi (2008). "Semi-nonparametric estimates of interfuel substitution in U.S. energy demand." Energy Economics 30:2123-2133. https://doi.org/10.1016/j.eneco.2007.09.002.

Sharimakin A., A.J. Glass, D.S. Saal, and K. Glass (2018). "Dynamic multilevel modelling of industrial energy demand in Europe” Energy Economics 74:120-130. https://doi.org/10.1016/j.eneco.2018.06.001.

Steinbuks, J. (2012). "Interfuel substitution and energy use in the UK manufacturing sector." The Energy Journal 33:1-29. https://doi.org/10.5547/ISSN0195-6574-EJ-Vol33-No1-1.

Stern, D.I. (2012). "Interfuel substitution: a meta-analysis." Journal of Economic Surveys 26:307-331. https://doi. org/10.1111/j.1467-6419.2010.00646.x.

Suh, D.H. (2016). “Interfuel substitution and biomass use in the US industrial sector: a differential approach.” Energy 102:24 30. https://doi.org/10.1016/j.energy.2016.02.012.

Taheri, A.A. and R. Stevenson (2002). "Energy price, environmental policy, and technological bias." The Energy Journal 23:85-107. https://doi.org/10.5547/ISSN0195-6574-EJ-Vol23-No4-4.

Taylor, L.D. (1975). “The Demand for Electricity: A Survey.” Bell Journal of Economics, Spring, 74-110. https://doi. org/10.2307/3003216.

Taylor, L.D. (1977). “The Demand for Energy: A Survey of Price and Income Elasticities.” In W. D. Nordhaus eds., International Studies of the Demand for Energy, Amsterdam: North Holland.

Uri, N.D. (1979). "Energy substitution in the UK 1948-64.” Energy Economics, 1:241-244. https://doi.org/10.1016/01409883(79)90006-9.

Uri, N.D. (1982). "Energy demand and interfuel substitution in the United Kingdom." Socio-Economic Planning Sciences 16:157-162. https://doi.org/10.1016/0038-0121(82)90033-7.

Westoby, R. (1984). "Models of interfuel substitution in the UK." Journal of Economic Studies 11:27-39. https://doi. org/10.1108/eb002571.

Zivot, E. and K. Andrews (1992). "Further Evidence on the Great Crash, the Oil Price Shock, and the Unit Root Hypothesis." Journal of Business and Economic Statistics 10:251-70. https://doi.org/10.1080/07350015.1992.10509904. 


\section{SUPPLEMENTAL INFORMATION}

Table A1: Matching between energy consumption and economic activity data for the industrial subsectors assessed in our study

\begin{tabular}{llr}
\hline Sector Identifier & \multicolumn{1}{c}{ Description } & DUKES energy data \\
\hline & & SIC 2007 code \\
FBT & Food, Beverages and Tobacco & $10-12$ \\
TEX & Textiles, Clothing, Leather and Footwear & $13-15$ \\
PPP & Pulp, Paper, Printing and Publishing & $17-18$ \\
CHE & Chemicals & $20-21$ \\
MIN & Non-Metallic Mineral products & 8,23 \\
ENV & Engineering and Vehicles & $25-30$ \\
NFM & Non-Ferrous Metals & Other \\
OTH & Other industries & 24.4, (excluding 24.46), 24.53, 24.54 \\
\hline
\end{tabular}

Table A2a: Results from unit root tests for electricity share

\begin{tabular}{|c|c|c|c|c|c|c|}
\hline & \multicolumn{3}{|c|}{ Levels } & \multicolumn{3}{|c|}{ Differences } \\
\hline & Test Statistic & Lags & tre/int & Test Statistic & Lags & tre/int \\
\hline $\mathrm{CHE}$ & -2.03 & 0 & trend & $-4.17^{(* *)}$ & 0 & constant \\
\hline ENV & -1.18 & 2 & constant & $-3.15^{(*)}$ & 0 & constant \\
\hline FBT & -2.29 & 0 & trend & $-4.78^{(* *)}$ & 0 & constant \\
\hline MIN & $-3.63^{(*)}$ & 0 & trend & $-4.75^{(* *)}$ & 0 & constant \\
\hline NFM & -1.72 & 0 & trend & -1.40 & 2 & constant \\
\hline OTH & -1.97 & 0 & trend & -1.13 & 2 & trend \\
\hline PPP & -3.01 & 0 & trend & $-5.34^{(* *)}$ & 0 & constant \\
\hline TEX & -2.79 & 0 & trend & $-6.16^{(* *)}$ & 0 & constant \\
\hline
\end{tabular}

A key to the acronyms of the industrial subsectors can be seen in Table A1. Key: $\left({ }^{* *}\right),(*)$ and $(+)$ indicate $1 \%, 5 \%$ and $10 \%$ significance level, respectively.

Table A2b: Results from unit root tests for gas share

\begin{tabular}{|c|c|c|c|c|c|c|}
\hline & \multicolumn{3}{|c|}{ Levels } & \multicolumn{3}{|c|}{ Differences } \\
\hline & Test Statistic & Lags & tre/int & Test Statistic & Lags & tre/int \\
\hline $\mathrm{CHE}$ & -1.52 & 0 & constant & 0.43 & 3 & trend \\
\hline ENV & -1.22 & 0 & constant & $-3.45^{(*)}$ & 0 & constant \\
\hline FBT & -1.76 & 0 & constant & -2.86 & 2 & trend \\
\hline MIN & -2.28 & 0 & constant & -2.26 & 2 & constant \\
\hline NFM & -1.64 & 0 & constant & -2.39 & 2 & constant \\
\hline OTH & -1.49 & 1 & trend & $-2.76^{(+)}$ & 2 & constant \\
\hline PPP & -1.85 & 3 & trend & $-4.64^{(* *)}$ & 0 & constant \\
\hline TEX & -1.71 & 1 & constant & $-6.00^{(* *)}$ & 0 & constant \\
\hline
\end{tabular}

A key to the acronyms of the industrial subsectors can be seen in Table A1. Key: $\left({ }^{* *}\right),\left({ }^{*}\right)$ and $(+)$ indicate $1 \%, 5 \%$ and $10 \%$ significance level, respectively.

Table A2c: Results from unit root tests for coal/oil share

\begin{tabular}{|c|c|c|c|c|c|c|}
\hline & \multicolumn{3}{|c|}{ Levels } & \multicolumn{3}{|c|}{ Differences } \\
\hline & Test Statistic & Lags & tre/int & Test Statistic & Lags & tre/int \\
\hline CHE & -1.34 & 1 & trend & $-6.56^{(* *)}$ & 0 & trend \\
\hline ENV & -1.39 & 2 & constant & $-3.61^{(*)}$ & 0 & constant \\
\hline FBT & -1.08 & 0 & constant & -1.89 & 2 & constant \\
\hline MIN (COAL) & -2.62 & 0 & constant & $-5.14^{(* *)}$ & 0 & constant \\
\hline NFM (COAL) & -0.89 & 2 & constant & -2.37 & 2 & constant \\
\hline OTH (COAL) & -0.16 & 2 & trend & $-6.21^{(* *)}$ & 0 & trend \\
\hline PPP & -1.32 & 0 & constant & $-4.99^{(* *)}$ & 0 & constant \\
\hline TEX & -2.11 & 0 & trend & $-4.15^{(* *)}$ & 0 & constant \\
\hline
\end{tabular}

A key to the acronyms of the industrial subsectors can be seen in Table A1. Key: ${ }^{(* *)},{ }^{(*)}$ and ${ }^{(+)}$indicate $1 \%, 5 \%$ and $10 \%$ significance level, respectively. 
Table A2d: Results from ZA unit root tests for shares appearing to be at least I(2) based on ADF unit root tests

\begin{tabular}{llrrrrrr}
\hline & & Statistic & Lags & Break date & Statistic & Lags & Break date \\
\hline \multirow{2}{*}{ ELE } & NFM & -2.27 & 0 & 2012 & $-7.17^{(* *)}$ & 1 & 2003 \\
& OTH & -4.23 & 2 & 2008 & $-8.21^{(* *)}$ & 1 & 2006 \\
\hline \multirow{4}{*}{ GAS } & CHE & -4.48 & 0 & 1999 & $-10.88^{(* *)}$ & 1 & 2007 \\
& FBT & -3.68 & 4 & 2012 & $-5.53^{(*)}$ & 2 & 2010 \\
& MIN & $-6.14(* *)$ & 4 & 2007 & $-6.41^{(* *)}$ & 0 & 2005 \\
\hline OIL & NFM & -3.00 & 0 & 2003 & $-6.16^{(* *)}$ & 1 & 2003 \\
COAL & FBT & -4.16 & 5 & 2012 & $-6.59^{(* *)}$ & 2 & 2000 \\
\hline
\end{tabular}

Acronyms of the sectors assessed in this study can be seen in Table A1 in the appendix. Key: $(* *),(*)$ and $(+)$ indicate $1 \%$, $5 \%$ and $10 \%$ significance level, respectively.

Table A3a: Results from unit root tests for relative electricity price

\begin{tabular}{|c|c|c|c|c|c|c|}
\hline & \multicolumn{3}{|c|}{ Levels } & \multicolumn{3}{|c|}{ Differences } \\
\hline & Test Statistic & Lags & tre/int & Test Statistic & Lags & tre/int \\
\hline CHE & -2.85 & 0 & trend & $-5.09^{(* *)}$ & 0 & constant \\
\hline ENV & -2.84 & 0 & trend & $-4.88^{(* *)}$ & 0 & constant \\
\hline FBT & -2.88 & 0 & trend & $-4.99^{(* *)}$ & 0 & constant \\
\hline MIN (COAL) & $-3.41^{(+)}$ & 0 & trend & $-6.67^{(* *)}$ & 0 & constant \\
\hline NFM (COAL) & -2.12 & 0 & constant & $-4.53^{(* *)}$ & 0 & constant \\
\hline OTH (COAL) & -2.22 & 0 & constant & -2.04 & 2 & constant \\
\hline PPP & -2.91 & 0 & trend & $-5.16^{(* *)}$ & 0 & constant \\
\hline TEX & -2.85 & 0 & trend & $-4.80^{(* *)}$ & 0 & constant \\
\hline
\end{tabular}

A key to the acronyms of the industrial subsectors can be seen in Table A1. Key: (**), (*) and (+) indicate $1 \%, 5 \%$ and $10 \%$ significance level, respectively. Energy consumption in OTH is I(1) based on the ZA test - value of the statistics being -5.97 for the first difference of the series. Relative electricity price in OTH is I(1) based on the ZA test—value of the statistics being -6.16 for the first difference of the series.

Table A3b: Results from unit root tests for relative gas price

\begin{tabular}{|c|c|c|c|c|c|c|}
\hline & \multicolumn{3}{|c|}{ Levels } & \multicolumn{3}{|c|}{ Differences } \\
\hline & Test Statistic & Lags & tre/int & Test Statistic & Lags & tre/int \\
\hline $\mathrm{CHE}$ & -1.96 & 2 & trend & $-5.50^{(* *)}$ & 0 & constant \\
\hline ENV & -1.97 & 2 & trend & $-5.45^{(* *)}$ & 0 & constant \\
\hline FBT & -1.97 & 2 & trend & $-5.49^{(* *)}$ & 0 & constant \\
\hline MIN (COAL) & -2.18 & 0 & trend & $-4.52^{(* *)}$ & 0 & constant \\
\hline NFM (COAL) & -2.12 & 0 & trend & $-5.37^{(* *)}$ & 0 & constant \\
\hline OTH (COAL) & -2.24 & 0 & trend & $-5.53^{(* *)}$ & 0 & constant \\
\hline PPP & -1.96 & 2 & trend & $-5.52^{(* *)}$ & 0 & constant \\
\hline TEX & -1.97 & 2 & trend & $-5.45^{(* *)}$ & 0 & constant \\
\hline
\end{tabular}

A key to the acronyms of the industrial subsectors can be seen in Table A1. Key: $(* *),(*)$ and $(+)$ indicate $1 \%, 5 \%$ and $10 \%$ significance level, respectively. 
Table A4a: Results from unit root tests for energy consumption

\begin{tabular}{|c|c|c|c|c|c|c|}
\hline & \multicolumn{3}{|c|}{ Levels } & \multicolumn{3}{|c|}{ Differences } \\
\hline & Test Statistic & Lags & tre/int & Test Statistic & Lags & tre/int \\
\hline CHE & -1.39 & 0 & trend & $-2.85^{(+)}$ & 3 & constant \\
\hline ENV & -1.71 & 0 & trend & $-3.75^{(*)}$ & 0 & constant \\
\hline FBT & -2.25 & 0 & trend & $-5.39^{(* *)}$ & 0 & constant \\
\hline MIN (COAL) & -3.21 & 0 & trend & $-5.62^{(* *)}$ & 0 & constant \\
\hline NFM (COAL) & -0.21 & 0 & trend & $-6.47^{(* *)}$ & 0 & constant \\
\hline OTH (COAL) & -1.70 & 0 & trend & -1.94 & 2 & constant \\
\hline PPP & -1.69 & 0 & trend & $-3.68^{(*)}$ & 0 & constant \\
\hline TEX & -2.40 & 0 & trend & $-5.72^{(* *)}$ & 0 & constant \\
\hline
\end{tabular}

A key to the acronyms of the industrial subsectors can be seen in Table A1. Key: $(* *),(*)$ and $(+)$ indicate $1 \%, 5 \%$ and $10 \%$ significance level, respectively. Energy consumption in OTH is I(1) based on the ZA test - value of the statistics being -5.97 for the first difference of the series.

Table A5: Results from the trace and max eigenvalue cointegration tests

\begin{tabular}{|c|c|c|c|c|c|c|c|c|}
\hline & \multicolumn{4}{|c|}{ Trace } & \multicolumn{4}{|c|}{ Max Eigenvalue } \\
\hline & $\mathbf{H}_{0}$ & $\mathrm{H}_{1}$ & $\lambda_{\text {trace }}$ & p-value & $\mathbf{H}_{0}$ & $\mathbf{H}_{1}$ & $\lambda_{\text {max }}$ & p-value \\
\hline \multirow[t]{3}{*}{ CHE } & $r=0$ & $r \geq 1$ & 102.76 & $0.00^{(* *)}$ & $r=0$ & $\mathrm{r}=1$ & 52.38 & $0.00^{(* *)}$ \\
\hline & $\mathrm{r} \leq 1$ & $r \geq 2$ & 50.38 & $0.03^{(*)}$ & $r=1$ & $r=2$ & 26.43 & $0.07^{(*)}$ \\
\hline & $\mathrm{r} \leq 2$ & $r \geq 3$ & 23.95 & 0.20 & $r=2$ & $r=3$ & 16.19 & 0.21 \\
\hline \multirow[t]{3}{*}{ ENV } & $r=0$ & $r \geq 1$ & 86.28 & $0.00^{(* *)}$ & $r=0$ & $\mathrm{r}=1$ & 41.20 & $0.01^{(* *)}$ \\
\hline & $r \leq 1$ & $r \geq 2$ & 45.08 & $0.09^{(+)}$ & $r=1$ & $r=2$ & 25.03 & $0.10^{(+)}$ \\
\hline & $r \leq 2$ & $r \geq 3$ & 20.05 & 0.42 & $r=2$ & $r=3$ & 14.08 & 0.36 \\
\hline \multirow[t]{3}{*}{ FBT } & $r=0$ & $r \geq 1$ & 64.67 & $0.00^{(* *)}$ & $r=0$ & $r=1$ & 31.87 & $0.01^{(* *)}$ \\
\hline & $r \leq 1$ & $r \geq 2$ & 32.80 & $0.02^{(* *)}$ & $r=1$ & $r=2$ & 21.21 & $0.05^{(*)}$ \\
\hline & $\mathrm{r} \leq 2$ & $r \geq 3$ & 11.59 & 0.18 & $r=2$ & $r=3$ & 9.61 & 0.24 \\
\hline \multirow[t]{3}{*}{ MIN } & $r=0$ & $r \geq 1$ & 98.85 & $0.01^{(* *)}$ & $r=0$ & $r=1$ & 40.28 & $0.03^{(*)}$ \\
\hline & $r \leq 1$ & $r \geq 2$ & 58.56 & 0.13 & $r=1$ & $r=2$ & 31.56 & $0.06^{(+)}$ \\
\hline & $r \leq 2$ & $r \geq 3$ & 27.00 & 0.68 & $r=2$ & $r=3$ & 13.55 & 0.76 \\
\hline \multirow[t]{3}{*}{ NFM } & $r=0$ & $r \geq 1$ & 62.88 & $0.06^{(+)}$ & $r=0$ & $r=1$ & 29.58 & $0.10^{(+)}$ \\
\hline & $r \leq 1$ & $r \geq 2$ & 33.29 & 0.32 & $r=1$ & $r=2$ & 19.15 & 0.30 \\
\hline & $r \leq 2$ & $r \geq 3$ & 14.14 & 0.65 & $r=2$ & $r=3$ & 8.01 & 0.82 \\
\hline \multirow[t]{3}{*}{ ОТН } & $r=0$ & $r \geq 1$ & 115.24 & $0.00^{(* *)}$ & $r=0$ & $r=1$ & 50.34 & $0.00^{(* *)}$ \\
\hline & $\mathrm{r} \leq 1$ & $r \geq 2$ & 64.89 & $0.00^{(* *)}$ & $r=1$ & $r=2$ & 25.54 & $0.09^{(+)}$ \\
\hline & $r \leq 2$ & $r \geq 3$ & 39.35 & $0.00^{(* *)}$ & $r=2$ & $r=3$ & 17.17 & 0.16 \\
\hline \multirow[t]{3}{*}{ PPP } & $r=0$ & $r \geq 1$ & 105.75 & $0.00^{(* *)}$ & $r=0$ & $r=1$ & 45.59 & $0.00^{(* *)}$ \\
\hline & $r \leq 1$ & $r \geq 2$ & 60.16 & $0.00^{(* *)}$ & $r=1$ & $r=2$ & 34.14 & $0.01^{(* *)}$ \\
\hline & $r \leq 2$ & $r \geq 3$ & 26.02 & 0.13 & $r=2$ & $r=3$ & 16.62 & 0.19 \\
\hline \multirow[t]{3}{*}{ TEX } & $r=0$ & $r \geq 1$ & 122.39 & $0.00^{(* *)}$ & $r=0$ & $r=1$ & 48.12 & $0.00^{(* *)}$ \\
\hline & $\mathrm{r} \leq 1$ & $r \geq 2$ & 74.27 & $0.01^{(* *)}$ & $r=1$ & $r=2$ & 29.67 & $0.10^{(+)}$ \\
\hline & $r \leq 2$ & $r \geq 3$ & 44.60 & $0.03^{(*)}$ & $r=2$ & $r=3$ & 19.14 & 0.30 \\
\hline
\end{tabular}

Key: $(* *),\left(^{*}\right)$ and $(+)$ indicate $1 \%, 5 \%$ and $10 \%$ significance level, respectively. A key to the acronyms of the industrial subsectors can be seen in Table A1. 


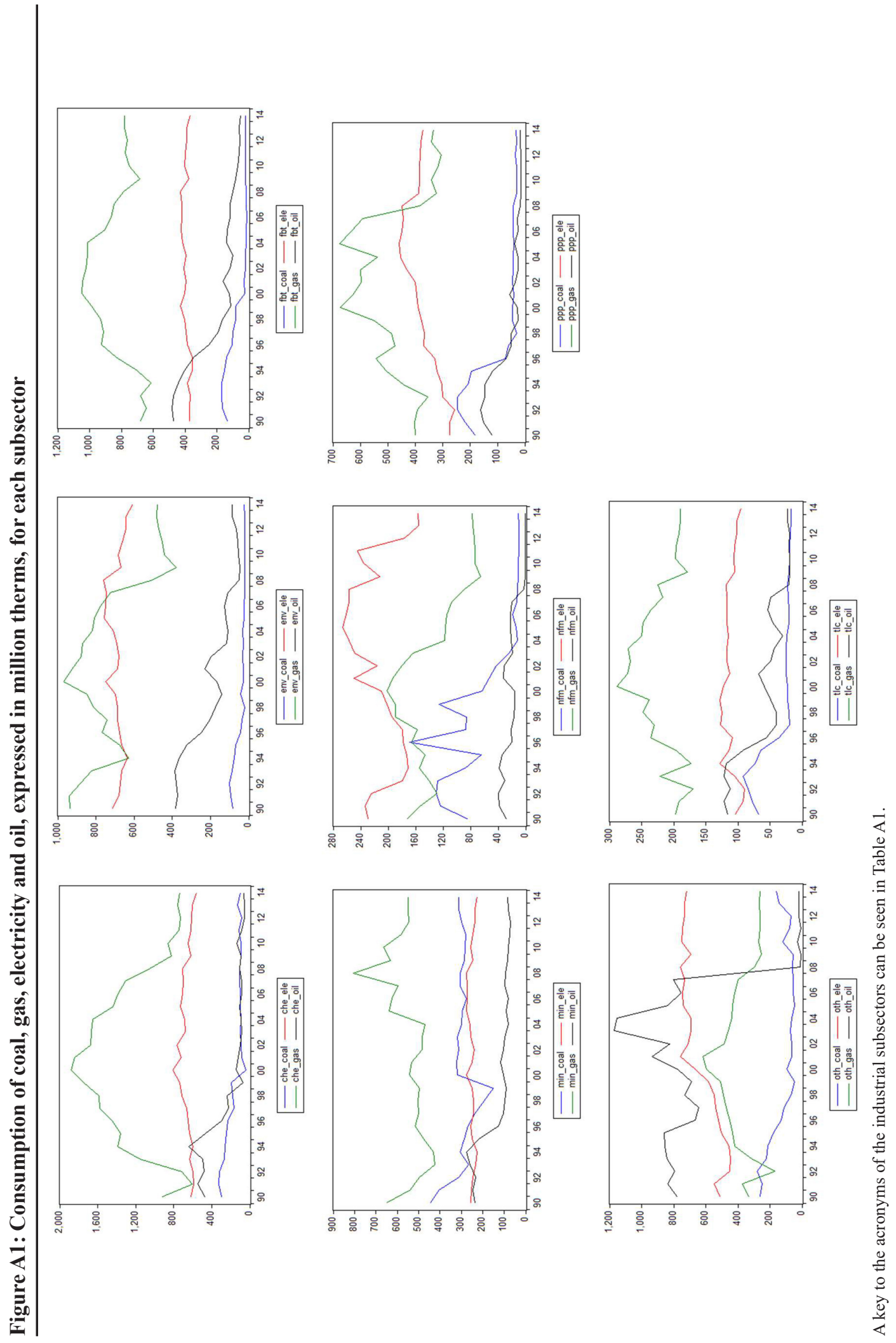




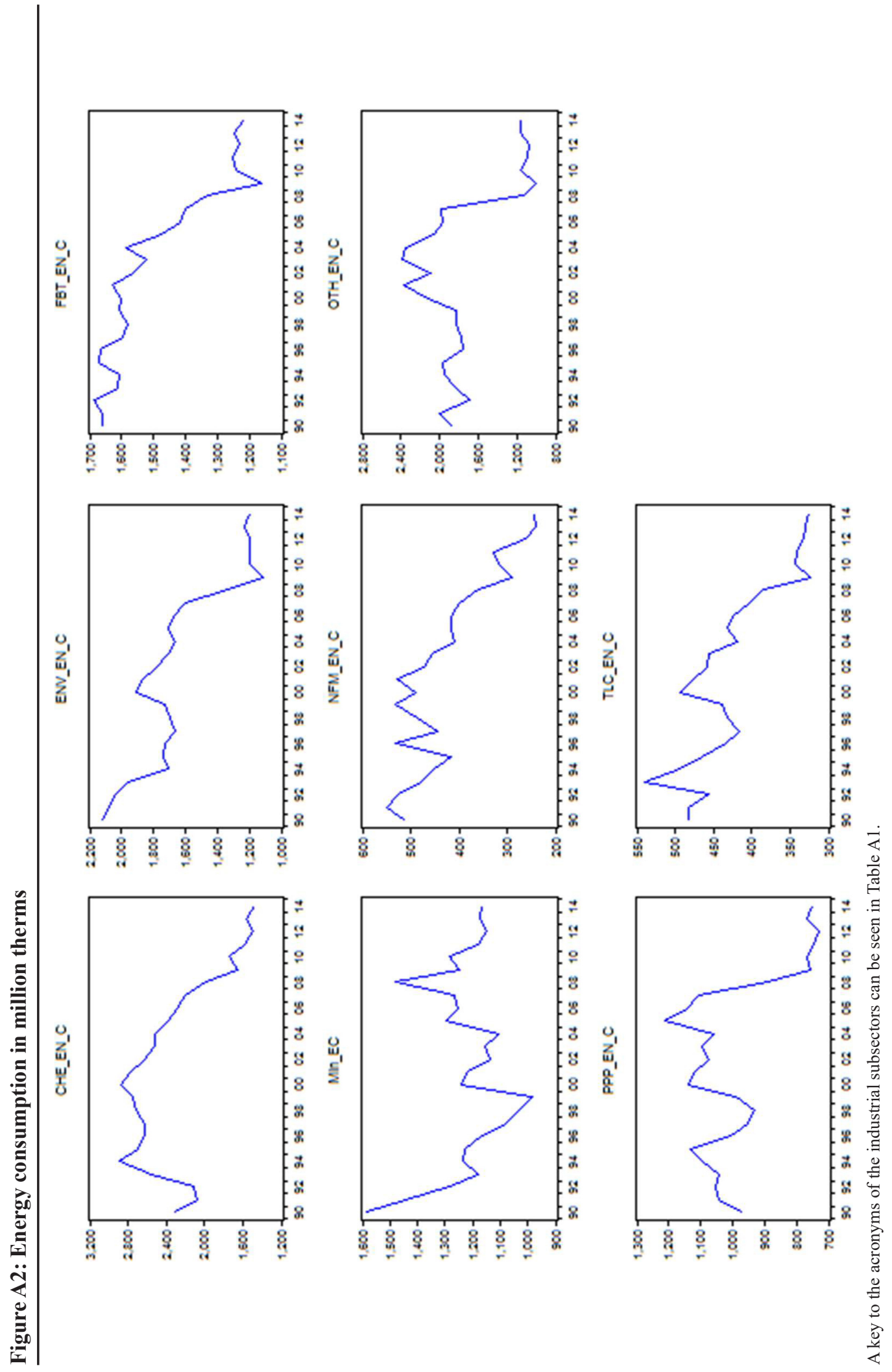



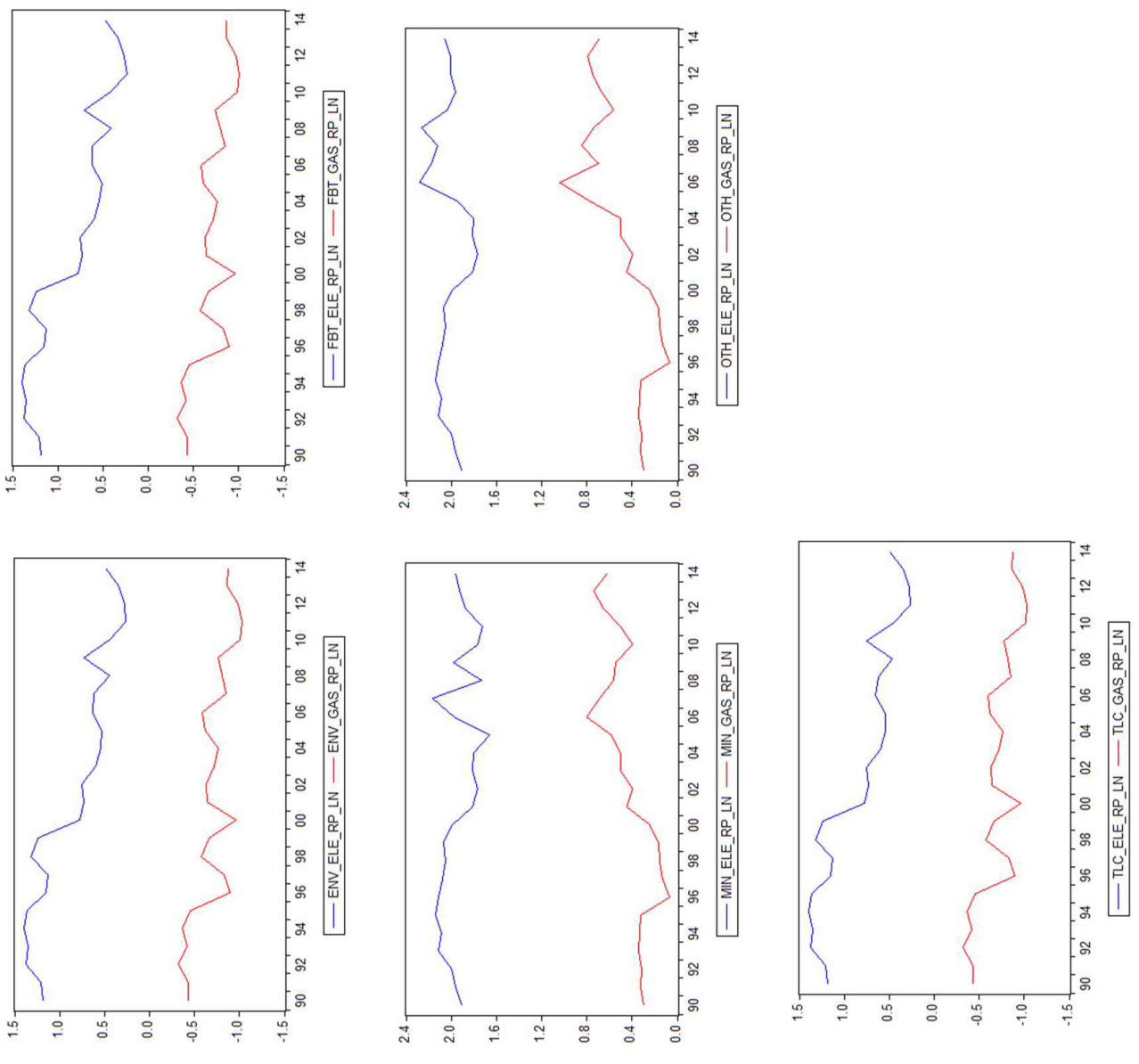

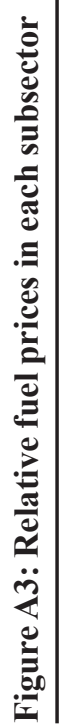
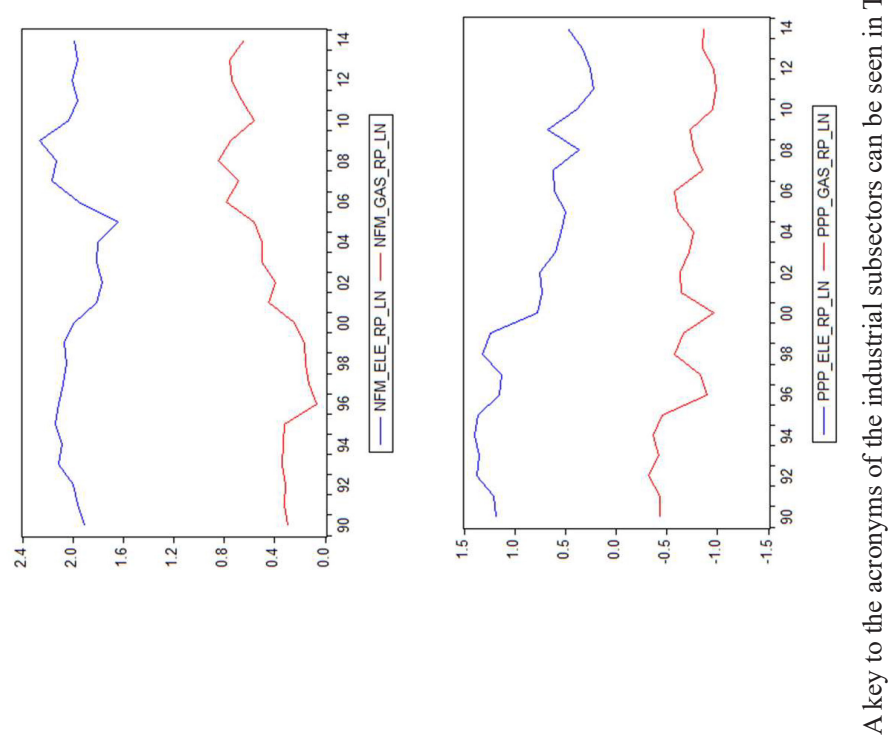

Open Access Article 